\title{
FOKUS EKONOMI
}

Jurnal IImiah Ekonomi

P-ISSN: 1907-1603

E-ISSN: 2549-8991

Acredited: SK No.: 21E/KPT/2018

Website : http://ejournal.stiepena.ac.id/index.php/fe

\section{PREDIKTOR DISPOSISIONAL ORGANIZATIONAL CITIZENSHIP BEHAVIOR (OCB) AGEN ASURANSI DAN MANAJER (STUDI PADA PERUSAHAAN ASURANSI DI JAWA TENGAH)}

\author{
B. Irmawati *) \\ Berta Bekti Retnawati **)
}

\begin{abstract}
Some variales in the organizational behavior that greatly affect the performance of employees are productivity, absenteeism, turnover, and job satisfaction, deviant behavior in the workplace and Organizational Citizenship Behavior. When associated with the empirical situation in business, in the field of insurance the role of sales force (insurance agent) becomes very important for the company. This profession requires the sales force to move closer to prospective customers both individuals and corporates. Their job is as corporate ambassadors / someone who is trusted to represent the company to promote, offer, and explain insurance products professionally, credibly and integrity. This study aims to examine the $O C B$ dispositional predictors of both insurance agents and managers. This research can contribute thoughts to the managerial practices of insurance industry business actors in improving organizational performance from Organizational Citizenship Behavior (OCB). The results of the analysis show that the OCB-I diagnostic model with the highest indicator is always willing to help customers and office guests who need help, then willing to help new employees to adapt to the work environment even though not ruled boss and as much as possible always keep up with the developments and changes that occur in the organization . Meanwhile the category that has an average score of four under the answer is willing to help ease the work of overloaded co-workers and the lowest is always complaining when there is a less ideal situation in the workplace. Basically, the agent's job is to find and maintain customers, agents work under supervisor and they can work in groups or independently. Group work is usually done by new agents who join the company, they follow the group as their place of learning in acquiring clients or customers. Experienced agents will be appointed as group leaders and manage the agents who are members. In this case the behavior of OCB-I can indicate an agent or group leader helps each other to achieve their target. From the OCB-O indicator, as a whole has a high category which means that the

*) Manajemen FEB Unika Soegijapranata

**) Magister Manajemen dan Manajemen FEB Unika Soegijapranata
\end{abstract}

Prediktor Disposisional Organizational Citizenship Behavior (OCB) Agen Asuransi dan Manager 
insurance agent is willing to comply with the regulations of the insurance company in which they work, the indicator that has the highest average value is that the agent never talks about bad things about the company outside and always adhere to all the company's rules and regulations, while the agency indicators are less actively involved in the activities in the company showed an average value of 3.37 indicates that the agent agent flexible working hours, according to the head of the insurance agent, the activities of insurance agents in the office varies, there is insurance that requires employees to come every morning for a meeting there stating they come at a weekend meeting to do an evaluation and make a plan for the next week. There is an insurance company that states that they are free to come to office to meet supervisornya (no schedule). The indicator that has the lowest average score and with the low category is the agent usually spend hours to talk about things out of work, relax, or play the game means the agent does not spend hours working for things that are not important because basically the agent has a target on his job and must meet clients or customers not to move on to another insurance company.

Keywords: Dispositional OCB, Insurance Agents

\section{Latar Belakang}

Dalam upaya pencapaian tujuan organisasi, sumber daya manusia mempunyai peran yang sangat penting disamping sumber-sumber daya lain yang dimiliki organisasi. Dalam kontkes perilaku organisasi, ada tiga faktor penentu perilaku dalam organisasi yaitu individu, kelompok, dan struktur. Ketiga hal tersebut dipelajari pengaruhnya pada organisasi dengan tujuan untuk menerapkan ilmu pengetahuan guna meningkatkan keefektifan suatu organisasi.

Peran sumber daya manusia khususnya dalam manajemen organisasi penjualan dengan armada tenaga penjualannya sangatlah penting (Piercy dkk.,2006) . Pertama, menjadi alat pemasaran yang mempertemukan langsung perusahaan dengan konsumen. Kedua, organisasi penjualan bertanggung-jawab terhadap sejumlah besar pengeluaran dan penerimaan pemasaran dalam kebanyakan perusahaan. Bahkan, bagi kebanyakan perusahaan didalam pasar-pasar industri, biaya penjualan langsung adalah jauh melebihi pengeluaran untuk periklanan media atau bentuk promosi penjualan lainnya. Ketiga, dalam era milenium baru ini organisasi-organisasi penjualan dihadapkan dengan sejumlah tantangan penting yang berasal dari perubahan-perubahan dari lingkungan yang secara dramatis merubah cara tenaga penjualan dan para manajer penjualan memahami, menyiapkan, dan menyelesaikan pekerjaan-pekerjaan mereka (Piercy dkk., 2006; Baldauf dan Cravens, 2002).

Peran mendasar organisasi penjualan dan tantangan kritis di masa penuh persaingan ini sangatlah penting bagi manajer penjualan dan perusahaan untuk menganalis berbagai hal yang berkaitan dengan kinerja tenaga penjualan. Banyak peneliti bidang manajemen pemasaran dan sumber daya manusia mengidentifikasi hal-hal yang dapat mempengaruhi 
kinerja tenaga penjualan (salesforce performance). Kinerja tenaga penjualan akan memiliki kinerja unggul bila target perusahaan tercapai (Baldauf dan Cravens, 2002).

Barisan tenaga penjualan dalam perusahaan memiliki peran strategik mengingat posisi mereka memungkinkan untuk; 1) berpeluang besar dalam mendapatkan informasi dari konsumenr untuk kemudian mengembangkannya dan mengimplementasikan kepada pasar sasaran sesuai karakteristik unik konsumen tersebut; dan 2) tenaga penjualan dapat secara langsung mengamati respon yang ditimbulkan dari strategi implementasi penjualan untuk selanjutnya melakukan perubahan yang dibutuhkan. Sementara menurut Judson dkk. (2006), mengatakan bahwa kinerja tenaga penjualan memiliki peran yang penting karena akan berdampak pada penciptaan keunggulan bersaing melalui pencapaian tujuan perusahaan, yaitu (1) peningkatan volume penjualan, (2) peningkatan profitabilitas dan (3) peningkatan kepuasan pelanggan.

Pembahasan kinerja tenaga penjualan tidak akan terlepas dari telaah mengenai kinerja perilaku tenaga penjualan (salesperson behavior performance). Kinerja perilaku mengindikasikan seberapa baik tenaga penjualan melaksanakan beragam aktifitas saat melakukan tanggung jawab pekerjaan mereka (Babakus dkk., 1996). Tenaga penjualan yang mampu mengontrol dimensi-dimensi dalam perilakunya diharapkan akan memberi pengaruh baik dalam hasil kinerjanya. Telaah mengenai dimensi-dimensi perilaku tenaga penjualan secara luas banyak dibahas dalam literatur penelitian tenaga penjualan. Studi Paparoidamis dan Guenzi (2009) memakai dimensi penjualan berorientasi pelanggan (customer-oriented selling) serta penjualan adaptif (adaptive selling). Berbeda lagi dengan studi Barker (2001) yang memasukkan motivasi, sales support orientation, teamwork, dan customer orientation sebagai dimensi-dimensi dalam kinerja perilaku tenaga penjual.

Dalam perilaku organisasi beberapa variabel yang sangat memberi pengaruh pada kinerja karyawan termasuk tenaga penjualan mencakup produktivitas, absensi, turnover, dan kepuasan kerja, perilaku menyimpang di tempat kerja dan Organizational Citizenship Behavior(OCB) (Robbins dan Judge, 2013). Organ (1988) menjelaskan bahwa OCB merupakan perilaku yang merupakan pilihan dan inisiatif individu, tidak terkait dengan sistem penghargaan yang berlaku pada organisasi tetapi keinginan untuk meningkatkan efektifitas organisasi. Triharjanti dan Irmawati (2007) meyatakan bahwa tidak adanya perbedaan OCB antara pria dan wanita sebagai tenaga pengajar menunjukkan mereka memberikan pelayanan yang baik kepada rekan kerja dan organisasi merupakan extra role behavior yag penting dalam karyawan bekerja. Modal relasional tenaga penjualan terbukti 
memberi pengaruh positif dalam mengelola interaksi dengan konsumen untuk menuju performa kinerja menjadi lebih baik (Retnawati, 2015). Sedangkan Finkelstein (2006) mengkaitkan kinerja tenaga penjualan dengan Organizational Citizenship Behavior (OCB) yang memberi bukti kuatnya pengaruh motivasi, pemenuhan motivasi, dan identitas peran dalam upaya peningkatan kinerja karyawan. Peran OCB sebagai salah satu bentuk perilaku extra-role, telah menarik perhatian dan perdebatan panjang di kalangan praktisi organisasi, peneliti maupun akademisi, dan sejauh ini tetap memberi kekuatan bagi peningkatan kinerja organisasi melalui kemauan para anggota untuk memberikan kontribusi pada organisasi (Lamm dkk., 2015).

Bila dikaitkan dengan situasi empirik dalam bisnis, dalam bidang asuransi peran tenaga penjualan (agen asuransi) menjadi sangat penting bagi perusahaan. Profesi ini mewajibkan tenaga penjualannya bergerak mendekati calon-calon konsumen baik individu maupun korporat. Tugas mereka adalah sebagai duta perusahaan/seseorang yang dipercaya untuk mewakili perusahaan guna mempromosikan, menawarkan, dan menjelaskan produk asuransi secara professional, kredibel, dan berintegritas. Seiring dengan perkembangan bisnis asuransi, dan meningkatnya kesadaran masyarakat akan pentingnya asuransi di Indonesia, sistem pemasaran asuransi (keagenan) semakin dituntut bekerja dengan lebih berkualitas menuju performa kinerja yang lebih baik (Retnawati dan Purwanto, 2004).

Para agen asuransi memposisikan diri sebagai konsultan keuangan jangka panjang bagi para nasabah. Para agen harus bisa memberikan konsultasi yang terbaik mengenai apa yang sebenarnya dibutuhkan oleh calon nasabah, sehingga mereka merasakan manfaatnya ketika mereka membeli polis asuransi. Ketika telah membeli polis, dan polis asuransi sudah terbit, tugas agen asuransi tidak hanya sampai di sini. Memberikan konsultasi, membina hubungan baik dengan para nasabah harus terus diakukan. Ini sangat penting, karena kepuasan nasabah akan memberikan dampak yang baik bagi setiap agen, terutama yang berhubungan dengan kepercayaan setiap calon-calon nasabah yang lain (Rahim, 2013).

Beberapa tantangan utama bisnis asuransi di tahun 2015 ini, mencakup tantangan pertama adalah mengenai perlambatan ekonomi yang akan menurunkan permintaan (demand) pasar asuransi dan juga kondisi pasar modal. Pertumbuhan asuransi umum tergantung kinerja sektor riil, sedangkan asuransi jiwa masih tergantung kondisi pasar modal. Kedua adalah tantangan kompetisi terbuka untuk menghadapi Masyarakat Ekonomi Asean (MEA) pada tahun 2015. Dengan penetrasi di bawah lima persen, pasar asuransi Indonesia akan diserbu perusahaan-perusahaan asuransi global, kondisi ini mensyaratkan terpenuhinya solusi akan kemampuan permodalan perusahaan nasional, sumber daya 
manusia di bidang asuransi, produk asuransi yang masih konvensional, serta minimnya literasi keuangan. Ketiga, Indonesia masih tertinggal jauh dibandingkan negara tetangga terkait jumlah agen-agen asuransi yang memiliki sertifikasi pada level internasional. Jumlah agen asuransi yang berlevel internasional masih kalah dibandingkan Filipina dan Singapura. Tahun 2014 ini jumlah agen di Indonesia yang terdaftar di Million Dollar Round Table (MDRT) yang merupakan standar internasional hanya 763 agen, itu peringkat ketiga setelah Filipina 1.000 agen dan Singapura 800 agen. Idealnya di tahun 2015 jumlah agen yang memiliki level internasional itu dapat bertambah setidaknya mencapai 1.000 orang. Seharusnya agen-agen di Indonesia sudah mulai terbuka pemikiran untuk meningkatkan kualitasnya dengan bergabung di asosiasi untuk berbagi ilmu dan pengalaman sehingga ada peningkatan jumlah MDRT di Indonesia dari tahun ke tahun (http://www.tempo.com/read/news/ 2 juli 2014, didownload tanggal 10 April 2015).

Penelitian ini ditujukan untuk membuat produk inovasi dalam bentuk pengembangan model peningkatan kinerja organisasi dengan mengembangkan model diagnosis Organizational Citizenship Behavior (OCB) yang bermanfaat untuk industri asuransi di Jawa tengah. Urgensi penelitian ini memberikan kontribusi pemikiran bagi praktik manajerial pelaku usaha industri asuransi dalam meningkatkan kinerja organisasi dari sisi Organizational Citizenship Behavior (OCB) .

\section{Tinjauan Pustaka}

\section{Organizational Citizenship Behavior (OCB): Definisi dan Dimensi}

Secara umum citizenship behavior merujuk pada 3 elemen utama yaitu, kepatuhan (obedience), loyalitas (loyalty), dan partisipasi. Kepatuhan dan loyalitas secara alami merupakan definisi citizenship dalam pengertian yang luas, sehingga esensi dari citizenship behavior adalah partisipasi. Dalam partisipasi, perhatian terutama ditujukan pada arena nasional (governance), arena komunal (local lives), dan arena organisasional (tempat kerja) (Finkelstein, 2006). Konseptualisasi $O C B$ dengan berbasiskan pada filosofi politik dan teori politik modern, ada tiga bentuk OCB yang mencakup (1) Ketaatan ( Obedience) yang menggambarkan kemauan karyawan untuk menerima dan mematuhi peraturan dan prosedur organisasi, (2) Loyalitas (Loyality) yang menggambarkan kemauan karyawan untuk menempatkan kepentingan pribadi mereka untuk keuntungan dan kelangsungan organisasi, dan (3) Partisipasi (Participation) yang menggambarkan kemauan karyawan untuk secara aktif mengembangkan seluruh aspek kehidupan organisasi (Bolino dkk., 2002). 
Organ (1988) mengkonseptualisasikan lima dimensi OCB mencakup altruism, conscientiousness, civic virtue, courtesy dan sportmanships. Dalam altruism merupakan perilaku yang membantu orang lain dalam menghadapi masalah dalam pekerjaannya. Conscientiousness mengacu pada perilaku seseorang yang tepat waktu, tingkat kehadiran tinggi, patuh pada aturan yang berlaku diorganisasi dan berada di atas persyaratan normal yang diharapkan. Civic virtue menunjukkan kontribusi terhadap isu-isu politik dalam suatu organisasi pada suatu tanggung jawab. Courtesy menunjukkan sikap sopan santun dan hormat yang ditunjukkan dalam setiap perilaku. Sportmanships menunjukkan seseorang yang tidak suka memprotes atau mengajukan ketidakpuasan terhadap masalah-masalah kecil.

\section{Konseptualisasi Organizational Citizenship Behavior Individu (OCB-I) dan Organizational Citizenship Behavior Organization (OCB-O)}

Konsep $O C B-I$ dan $O C B-O$ awalnya dikembangkan oleh Williams dan Anderson (1991), yang menyatakan bahwa $O C B-I$ adalah perilaku yang diarahkan pada individu dan $O C B-O$ adalah perilaku yang diarahkan pada organisasi. William dan Anderson (1991) mengelompokan lima dimensi dari Organ (1988) kedalam OCB-I yaitu altruism dan courtesy serta $O C B-O$ yaitu conscientiousness, civic virtue dan sportsmanship.

$O C B-I$ adalah upaya dan perhatian membantu pekerjaan rekan kerja yang masih baru, memberi pendampingan pada rekan kerja yang menghadapi masalah berkaitan dengan pekerjaan, ringan tangan, mudah memberi bantuan dan perhatian dan secara tidak langsung mempengaruhi efektivitas organisasi (Lee \& Allen, 2002; Williams \& Anderson, 1991). Sementara $O C B-O$ pendorong karyawan melakukan $O C B$ lebih dikarenakan keinginan berkontribusi pada tataran organisasi, seperti misal penawaran ide perbaikan fungsi organisasi, implementasi ide inovasi bagi department yang bisa secara langsung memberikan manfaat baik bagi pihak lain (organisasi ataupun atasan), juga sikap yang mengarah pada moral kemasyarakatan.

Beberapa peneliti seperti Aryee dkk (2002), Finkelestein (2006), Alizadeh dkk., 2012, Sesen dkk., 2014 dan Harper dan College (2015) mendasarkan pada William dan Anderson (1991) yaitu $O C B-I$ dan $O C B-O$ dengan menambahkan beberapa variabel seperti motivasi, kejelasan tugas, kepemimpinan, komitmen organisasional yang dikaitkan dengan kinerja individu,kelompok dan organisasi.

\section{Peran Tenaga Penjualan Asuransi Indonesia: Tantangan ke Depan}

Bisnis asuransi memiliki kekhasan cara pendekatan kepada calon pemegang polis secara intens, hal ini tidak terlepas dari karakter produk asuransi di Indonesia yang masih 
membutuhkan persuasif secara intens dari pihak perusahaan kepada para konsumennya. Peran tenaga penjualan/agen asuransi menjadi vital dan berperan penting dalam menunjang kinerja perusahaan. Selain kompetensi pemahaman produk, dapat mengetahui permintaan atau kebutuhan klien sehingga dapat menyesuaikannya dengan produk asuransi yang ditawarkan. seorang agen dituntut memiliki modal perilaku kesabaran, semangat kerja keras, loyalitas, jujur, dan pantang menyerah agar mampu memberikan pemahaman-bukan hanya informasi-yang baik kepada klien mengenai asuransi.

Untuk menuju tenaga penjualan yang profesional dan siap bersaing di era kompetisi global dibutuhkan agen bersertifikasi.Otoritas Jasa Keuangan (OJK) mencatat, ada lebih dari 100.000 tenaga pemasar atau agen asuransi jiwa dan asuransi umum yang belum mengantongi sertifikasi profesi. Tepatnya, 106.463 agen. Itu berarti, 24 persen dari total agen asuransi jiwa dan umum yang jumlahnya mencapai 435.605 agen. Namun demikian agen bersertifikasi masih sangat perlu ditingkatkan jumlahnya (http://bisniskeuangan.kompas.com/13 okt 2014, didownload tanggal 8 April 2015).

Pemerintah berupaya secara konsisten memantau dan membenahi kualitas Agen Asuransi harus bersertifikat lewat Surat Kepala Biro Perasuransian Nomor : S-3926/BL/2011 tertanggal 15 April 2011 (http://finansial.bisnis.com/ 10 feb 2015, didownload tanggal 8 April 2015). Profesionalitas tenaga penjualan asuransi dengan adanya ketentuan pemerintah untuk mendapatkan sertifikasi adalah sebagai berikut: (1) Agen Asuransi harus memiliki sertifikat yang dikeluarkan oleh Asosiasi terkait (2) Agen yang tidak bersertifikat tidak boleh menjual asuransi, mengirim penawaran asuransi dan menandatangani kontrak/ perjanjian asuransi dan (3) Perusahaan asuransi tidak boleh membayar komisi asuransi kepada Agen Asuransi yang tidak bersertifikat.

\section{Pembahasan}

Secara umum perusahaan asuransi perusahaaan asuransi terbagi menjadi dua yaitu perusahaan asuransi umum dan asuransi jiwa. Produk yang dijual berbeda, untuk perusahaan asuransi umum seperti asuransi kebakaran, kehilangan kendaraan, bangunan, dsb. Sedangkan perusahaan asuransi jiwa berupa asuransi perlindungan individu atas kesehatan, kecelakaan kerja dan investasi. Agen secagai frontliner perusahaan asuransi di Indonesia tidak berstatus sebagai karyawan tetap, agen bekerja tidak terbatas oelh ruang dan waktu, mereka bahkan menentukan gaji sendiri berdasar jumlah kliendanjenis produk asuransi. Setiap agen asuransi dapat menjalankan tugasnya setelah mereka memiliki sertifikasi profesi sebagai agen dan 
bernaung pada satu perusahaan asuransi. Berikut adalah gambaran umum responden pemimpin dan agen asuransi.

Tabel 1. Gambaran Umum Responden

\begin{tabular}{|c|c|c|c|c|}
\hline & \multicolumn{2}{|c|}{ Pimpinan Asuransi } & \multicolumn{2}{|c|}{ Agen Asuransi } \\
\hline & $\mathrm{F}$ & $\%$ & $\mathrm{~F}$ & $\%$ \\
\hline \multicolumn{5}{|l|}{ Gender } \\
\hline Laki-laki & 15 & 60 & 11 & 37,93 \\
\hline Perempuan & 10 & 40 & 18 & 62,07 \\
\hline \multicolumn{5}{|l|}{ Umur } \\
\hline 25-35 Tahun & 5 & 20 & 18 & 62,07 \\
\hline 36-45 Tahun & 10 & 40 & 7 & 24,14 \\
\hline 46-55 Tahun & 10 & 40 & 4 & 13,79 \\
\hline \multicolumn{5}{|l|}{ Pendidikan } \\
\hline SMA & 0 & 0 & 4 & 13,79 \\
\hline D3 & 0 & 0 & 4 & 13,79 \\
\hline S1 & 25 & 100 & 21 & 72,42 \\
\hline \multicolumn{5}{|c|}{ Lama Bekerja } \\
\hline $1-5$ & & & 25 & 86,20 \\
\hline $6-10$ & 13 & 30 & 2 & 6,90 \\
\hline$>10$ & 12 & 70 & 2 & 6,90 \\
\hline
\end{tabular}

Sumber : Data primer yang diolah, 2018

Berdasar tabel diatas diketahui bahwa responden yang menjadi agen asuransi perempuan $(62,07 \%)$ lebih banyak dibanding laki-laki $(37,93 \%)$, hal ini dikarenakan bahwa menjadi agen asuransi dari sisi jam kerja lebih fleksibel. Dari sisi pendidikan pimpinan asuransi 100\% berpendidikan S1 dan dari agen sebanyak 72,42 \%. Sedangkan dari sisi lama bekerja pimpinan 70\% sudah bergelar dengan pekerjaan bidang asuransi lebih dari 10 tahun, sedangkan agen sebagian besar ( 86,20\%) baru bekerja 1 sampai dengan 5 tahun.

\section{Analisis $O C B$ dari perspektif manajemen}

Pada dimensi OCB-I, indikator yang ditanyakan pada pimpinan adalah agen bisa saling bekerja sama dan saling membantu satu sama lain, pimpinan asuransi menyatakan bahwa agen melakukan pekerjaan masing-masing dan hanya bertemu dikantor mereka pada saat briefing, training agen melakukan pekerjaan mereka secara individual. Para agen asuransi melakukan relasi secara pribadi baik dengan sesama agen perusahaan asuransi maupuan yang lain. Ada perusahaan asuransi dimana para agen masuk dalam satu kelompok dengan satu pimpinan, mereka saling belajar dalam kelompok tersebut. Relasi agen dengan 
agen perusahaan lain terjadi apabila klien mencari produk yang tidak ditawarkan oleh perusahaan agen tetapi dijual oleh perusahaan asuransi yang lain.

Pada Dimensi OCB-O, indikator pertama adalah agen selalu hadir dikantor setiap hari, pimpinan menyatakan bahwa agen tidak diwajibkan datang kekantor setiap harinya tetapi mereka wajib hadir dalam pertemuan evaluasi yang telah ditetapkan masing-masing perusahaan. Pimpinan bahkan berharap agar agen lebih sering di luar kantor untuk menarik klien baru atau berelasi dengan klien yang sudah mereka tangani. Indikator yag kedua adalah agen mentaati perauturan perusahaan, pimpinan menyatakanbahwa agen saat ini bekerja sesuai aturan perusahaan, agen keluar dari perusahaan biasanya terjadi bila agen sudah tidak lagi nyaman bekerja sebagai agen.Turn over agen di perusahaan asuransi cukup tinggi,agen pindah dari asuransi satu ke asuransi yang lain adalah hal yang bisas terjadi walaupun ada jeda waktu.

\section{Analisis $O C B$ dari persektif agen asuransi.}

Berdasar kuesioner OCB yang dibagikan kepada responden, dapatlah dilihat hasil sbb:

Tabel 2. Tanggapan Agen Asuransi mengenai OCB-I dan OCB-O

\begin{tabular}{|c|c|c|c|}
\hline No & Pernyataan & $\begin{array}{c}\text { Nilai } \\
\text { Rata-Rata } \\
\end{array}$ & Kategori \\
\hline \multicolumn{4}{|c|}{ OCB-I } \\
\hline 1 & $\begin{array}{l}\text { Saya bersedia membantu meringankan pekerjaan rekan } \\
\text { kerja yang overload }\end{array}$ & 3,24 & Tinggi \\
\hline 2 & $\begin{array}{l}\text { Saya selalu bersedia membantu pelanggan dan tamu kantor } \\
\text { yang membutuhkan bantuan }\end{array}$ & 4,24 & Tinggi \\
\hline 3 & $\begin{array}{l}\text { Saya bersedia membantu pegawai baru beradaptasi dengan } \\
\text { Lingkungan kerja walapupun tidak diperintah atasan }\end{array}$ & 4,07 & Tinggi \\
\hline 4 & $\begin{array}{l}\text { Saya selalu memberikan informasi dan konsultasi pada } \\
\text { supervisor berhubungan dengan pekerjaan }\end{array}$ & 3,89 & Tinggi \\
\hline 5 & $\begin{array}{l}\text { Saya bersedia dengan lapangdada menerima kritikan dari } \\
\text { atasan dan rekan kerja mengenai pekerjaan }\end{array}$ & 3,89 & Tinggi \\
\hline 6 & $\begin{array}{l}\text { Saya sebisa mungkin selalu mengikuti perkembangan dan } \\
\text { perubahan yang terjadi dalam organisasi }\end{array}$ & 4,10 & Tinggi \\
\hline 7 & $\begin{array}{l}\text { Saya selalu mengeluh bila ada situasi yang kurang ideal di } \\
\text { tempat kerja }\end{array}$ & 3,14 & Tinggi \\
\hline 8 & $\begin{array}{l}\text { Saya tidak menyalahkan orang lain atas kegagalan tim } \\
\text { dalam pekerjaan }\end{array}$ & 3,86 & Tinggi \\
\hline \multicolumn{4}{|c|}{ OCB-O } \\
\hline 9 & $\begin{array}{l}\text { Saya kurang aktif terlibat dalam kegiatan-kegiatan di } \\
\text { perusahaan }\end{array}$ & 3,37 & Tinggi \\
\hline 10 & $\begin{array}{l}\text { Saya tidak pernah membicarakan hal-hal buruk tentang } \\
\text { perusahaan di luar }\end{array}$ & 4,14 & Tinggi \\
\hline
\end{tabular}




\begin{tabular}{|c|c|c|c|}
\hline No & Pernyataan & $\begin{array}{c}\text { Nilai } \\
\text { Rata-Rata }\end{array}$ & Kategori \\
\hline \multicolumn{4}{|c|}{ OCB-I } \\
\hline 11 & $\begin{array}{l}\text { Saya selalu memberi kritik membangun untuk peningkatan } \\
\text { kualitas perusahaan }\end{array}$ & 3,41 & Tinggi \\
\hline 12 & $\begin{array}{l}\text { Saya selalu mematuhi semua tata-tertib dan peraturan } \\
\text { perusahaan }\end{array}$ & 4,03 & Tinggi \\
\hline 13 & $\begin{array}{l}\text { Saya selalu tiba lebih awal dikantor sehingga bisa memulai } \\
\text { tugas lebih awal }\end{array}$ & 3,69 & Tinggi \\
\hline 14 & $\begin{array}{l}\text { Saya selalu siap sedia untuk bekerja lembur bila } \\
\text { dibutuhkan }\end{array}$ & 3,52 & Tinggi \\
\hline 15 & $\begin{array}{l}\text { Saya biasanya menghabiskan jam kerja untuk } \\
\text { membicarakan hal-hal diluar pekerjaan, bersantai, } \\
\text { atau main game }\end{array}$ & 3,07 & Rendah \\
\hline
\end{tabular}

Sumber : Data primer yang diolah, 2018

Dari tabel diatas menunjukkan OCB-I dengan indikator yang paling tinggi adalah selalu bersedia membantu pelanggan dan tamu kantor yang membutuhkan bantuan, kemudian bersedia membantu pegawai baru beradaptasi dengan lingkungan kerja walapupun tidak diperintah atasan dan sebisa mungkin selalu mengikuti perkembangan dan perubahan yang terjadi dalam organisasi. Sementara itu kategori yang memiliki nilai ratarata jawaban dibawah empat adalah bersedia membantu meringankan pekerjaan rekan kerja yang overload dan yang paling rendah adalah selalu mengeluh bila ada situasi yang kurang ideal di tempat kerja. Pada dasarnya pekerjaan agen adalah mencari dan memelihara pelanggan, para agen bekerja dibawah supervisor dan mereka bisa bekerja secara kelompok ataupun mandiri. Bekerja kelompok biasanya dilakukan oleh para agen yang baru bergabung dengan perusahaan, mereka mengikuti kelompok sebagai tempat belajar mereka dalam memperoleh klien atau pelanggan. Agen yang sudah berpengalaman akan ditunjuk sebagai pemimpin kelompok dan mengelola agen yang menjadi anggotanya. Dalam hal ini perilaku OCB-I dapat menunjukkan seorang agen ataupun pemimin kelompoksaling membantu agar target yang menjadi tujuan mereka tercapai.

Dari indikator OCB-O, secara keseluruhan memiliki kategori tinggi yang artinya agen asuransi mau mematuhi peraturan yang ada pada perusahaan asuransi dimana mereka bekerja, indikator yang memiliki nilai rata-rata paling tinggi adalah agen tidak pernah membicarakan hal-hal buruk tentang perusahaan di luar dan selalu mematuhi semua tatatertib dan peraturan perusahaan, sedangkan indikator agen kurang aktif terlibat dalam kegiatan-kegiatan di perusahaan menunjukkan nilai rata rata 3,37 menunjukkan bahwa agen jam kerja agen asuransi fleksibel, menurut pimpinan agen asuransi , kegiatan agen asuransi 
di kantor bervariasi, ada asuransi yang mengharuskan karyawan datang setiap pagi untuk pertemuan ada yang menyatakan mereka datang pada pertemuan akhir minggu untuk melakukan evaluasi dan membuat perencaan untuk minggu depannya. Ada perusahaan asuransi yang menyatakan bahwa mereka bebas datang kekantor untuk bertemu supervisornya (tanpa jadwal). Indikator yang memiliki nilai rata rata paling rendah dan dengan kategori rendah adalah agen biasanya menghabiskan jam kerja untuk membicarakan hal-hal diluar pekerjaan, bersantai, atau main game artinya agen tidak menghabiskan jam kerjanya untuk hal hal yang tidak penting karena pada dasarnya agen memiliki target pada pekerjaannya dan harus menemui klien atau pelanggan untuk tidak berpindah pada perusahaan asuransi yang lain.

\section{Simpulan dan Saran}

Secara umum perusahaan asuransi perusahaaan asuransi terbagi menjadi dua yaitu perusahaan asuransi umum dan asuransi jiwa. Produk yang dijual berbeda, untuk perusahaan asuransi umum seperti asuransi kebakaran, kehilangan kendaraan, bangunan, dsb. Sedangkan perusahaan asuransi jiwa berupa asuransi perlindungan individu atas kesehatan, kecelakaan kerja dan investasi. Agen secagai frontliner perusahaan asuransi di Indonesia tidak berstatus sebagai karyawan tetap, agen bekerja tidak terbatas oelh ruang dan waktu, mereka bahkan menentukan gaji sendiri berdasar jumlah kliendanjenis produk asuransi.

Kesimpulan sementara dari pengumpulan data dan analisis yang masih terbatas adalah responden yang menjadi agen asuransi perempuan (62,07\%) lebih banyak dibanding laki-laki (37,93\%), hal ini dikarenakan bahwa menjadi agen asuransi dari sisi jam kerja lebih fleksibel. Dari sisi pendidikan pimpinan asuransi 100\% berpendidikan S1 dan dari agen sebanyak 72,42\%. Sedangkan dari sisi lama bekerja pimpinan 70\% sudah bergelar dengan pekerjaan bidang asuransi lebih dari 10 tahun, sedangkan agen sebagian besar ( $86,20 \%)$ baru bekerja 1 sampai dengan 5 tahun.

Pada dimensi OCB-I, indicator-indikator mencakup apakah agen bisa saling bekerja sama dan saling membantu satu sama lain, pimpinan asuransi menyatakan bahwa agen melakukan pekerjaan masing-masing dan hanya bertemu dikantor mereka pada saat briefing, training agen melakukan pekerjaan mereka secara individual. Para agen asuransi melakukan relasi secara pribadi baik dengan sesama agen perusahaan asuransi maupuan yang lain. Ada perusahaan asuransi dimana para agen masuk dalam satu kelompok dengan satu pimpinan, mereka saling belajar dalam kelompok tersebut. Relasi agen dengan agen perusahaan lain 
terjadi apabila klien mencari produk yang tidak ditawarkan oleh perusahaan agen tetapi dijual oleh perusahaan asuransi yang lain.

Pada Dimensi OCB-O, indikator pertama adalah agen selalu hadir dikantor setiap hari, pimpinan menyatakan bahwa agen tidak diwajibkan datang kekantor setiap harinya tetapi mereka wajib hadir dalam pertemuan evaluasi yang telah ditetapkan masing-masing perusahaan. Pimpinan bahkan berharap agar agen lebih sering di luar kantor untuk menarik klien baru atau berelasi dengan klien yang sudah mereka tangani. Indikator yag kedua adalah agen mentaati perauturan perusahaan, pimpinan menyatakanbahwa agen saat ini bekerja sesuai aturan perusahaan, agen keluar dari perusahaan biasanya terjadi bila agen sudah tidak lagi nyaman bekerja sebagai agen.Turn over agen di perusahaan asuransi cukup tinggi,agen pindah dari asuransi satu ke asuransi yang lain adalah hal yang bias terjadi walaupun ada jeda waktu.

Analisis OCB dari persektif agen asuransi, berdasar kuesioner OCB yang dibagikan kepada responden, dapatlah dilihat hasil sebagai berikut: OCB-I dengan indikator yang paling tinggi adalah selalu bersedia membantu pelanggan dan tamu kantor yang membutuhkan bantuan, kemudian bersedia membantu pegawai baru beradaptasi dengan lingkungan kerja walapupun tidak diperintah atasan dan sebisa mungkin selalu mengikuti perkembangan dan perubahan yang terjadi dalam organisasi. Sementara itu kategori yang memiliki nilai rata-rata jawaban dibawah empat adalah bersedia membantu meringankan pekerjaan rekan kerja yang overload dan yang paling rendah adalah selalu mengeluh bila ada situasi yang kurang ideal di tempat kerja. Pada dasarnya pekerjaan agen adalah mencari dan memelihara pelanggan, para agen bekerja dibawah supervisor dan mereka bisa bekerja secara kelompok ataupun mandiri. Bekerja kelompok biasanya dilakukan oleh para agen yang baru bergabung dengan perusahaan, mereka mengikuti kelompok sebagai tempat belajar mereka dalam memperoleh klien atau pelanggan. Agen yang sudah berpengalaman akan ditunjuk sebagai pemimpin kelompok dan mengelola agen yang menjadi anggotanya. Dalam hal ini perilaku OCB-I dapat menunjukkan seorang agen ataupun pemimin kelompoksaling membantu agar target yang menjadi tujuan mereka tercapai.

Dari indikator OCB-O, secara keseluruhan memiliki kategori tinggi yang artinya agen asuransi mau mematuhi peraturan yang ada pada perusahaan asuransi dimana mereka bekerja, indikator yang memiliki nilai rata-rata paling tinggi adalah agen tidak pernah membicarakan hal-hal buruk tentang perusahaan di luar dan selalu mematuhi semua tatatertib dan peraturan perusahaan, sedangkan indikator agen kurang aktif terlibat dalam kegiatan-kegiatan di perusahaan menunjukkan nilai rata rata 3,37 menunjukkan bahwa agen 
jam kerja agen asuransi fleksibel, menurut pimpinan agen asuransi , kegiatan agen asuransi di kantor bervariasi, ada asuransi yang mengharuskan karyawan datang setiap pagi untuk pertemuan ada yang menyatakan mereka datang pada pertemuan akhir minggu untuk melakukan evaluasi dan membuat perencaan untuk minggu depannya. Ada perusahaan asuransi yang menyatakan bahwa mereka bebas datang kekantor untuk bertemu supervisornya (tanpa jadwal). Indikator yang memiliki nilai rata rata paling rendah dan dengan kategori rendah adalah agen biasanya menghabiskan jam kerja untuk membicarakan hal-hal diluar pekerjaan, bersantai, atau main game artinya agen tidak menghabiskan jam kerjanya untuk hal hal yang tidak penting karena pada dasarnya agen memiliki target pada pekerjaannya dan harus menemui klien atau pelanggan untuk tidak berpindah pada perusahaan asuransi yang lain.

\section{Daftar Pustaka}

Aryee, S., P. S. Budhwar, dan Z. X. Chen. 2002. Trust as a Mediator of the Relationship between Organizational Justice and Work Outcomes: Test a Social Exchange Model. Journal of Organizational Behavior 23 (3):267-285.

Baldauf, A., dan D. Cravens. 2002. The Effect of Moderaotor European Journal of Marketing 36 (11/12):1367-1388.

Barker, A. T. 1999. Benchmarks of Successful Salesforce Performance Canadian Journal of Administrative Sciences/Revue Canadienne des Sciences de l'Administration 16 (2):95-104.

2001. Salespeople Characteristics, Sales Managers' Activities and Territory Design as Antecedents of Sales Organization Performance Marketing Intelligence \& Planning 19 (1):21-28.

Bolino, M. C., W. H. Turnley, dan J. M. Bloodgood. 2002. Citizenhsip Behavior and the Creation of Social Capital in Organizations. Academy of Management Review 27 (4):505-522.

Finkelstein, M. A. 2006. Dispositional Predictors of Organizational Citizenship Behavior: Motives, Motive Fulfillment, and Role Identity. Social Behavior and Personality 34 (6):603-616..

Harper , P., J, dan College , M. 2015 . Exploring forms of organizational citizenship 
behaviors (OCB): antecedents and outcomes , Journal of Management and Marketing Research, Vol 6 (1-16)

Judson, K., D. D. Schoenbachler, G. L. Gordon, R. E. Ridnour, dan D. C. Weilbaker. 2006. The New Product Development Process: Let the Voice of the Salesperson Be Heard Journal of Product \& Brand Management 15 (3):194-202.

Lamm, E., J. Tosti-Kharas, dan C. E. King. 2015. Empowering Employee Sustainability: Perceived Organizational Support toward the Environment Journal Business Ethics 128:207-220.

Laporan Perasuransian, 2011

Nafei, W. 2015. The Role of Job Embeddedness on Quality of Work Life and Organizational Citizenship Behavior: A Study on Menoufia University Hospitals International Journal of Business and Management 10 (4):215-230.

Paparoidamis, N. G., dan P. Guenzi. 2009. An Empirical Investigation into the Impact of Relationship Selling and Lmx on Salespeople's Behaviours and Sales Effectiveness. European Journal of Marketing 43 (7/8):1053-1075.

Piercy, N. F., D. W. Cravens, dan N. Lane. 2012. Sales Manager Behavior-Based Control and Salesperson Performance: The Effects of Manager Control Competencies and Organizational Citizenship Behavior Journal of Marketing Theory and Practice 20 (1):7-22.

Piercy, N. F., D. W. Cravens, N. Lane, dan D. W. Vorhies. 2006. Driving Organizational Citizenship Behaviors and Salesperson in-Role of Management Control and Perceived Organizational Support. Academy of Marketing Science. 34 (2):244262.

Piercy, N. F., D. W. Cravens, dan N. A. Morgan. 1998a. Salesforce Performance and Behaviour-Based Management Processes in Business-Tobusiness Sales Organizations European Journal of Marketing 32 (1/2):79-100.

1998b. Salesforce Performance and Behaviour-Based Management Processes in Business-Tobusiness Sales Organizations European Journal of Marketing 32 (1/2):79-100.

Podsakoff, P. M., S. B. MacKenzie, J. B. Paine, dan D. G. Bachrach. 2000. Organizational Citizenship Behavior: A Critical Review of Theoretical Empirical Literature and Suggestions for Future Research. Journal of Management 26 (3):513-563.

Rahim, H. 2013. Optimisme Pertumbuhan Asuransi Indonesia; Proyeksi Perkembangan Lima Tahun (2014-2018). Jurnal Asuransi dan Manajemen Risiko 1 (2):1-21. 
Retnawati, B. B. 2015. Role of Relational Capital and Customer Relationship to Strengthening Salesperson Performance.

Retnawati, B. B., dan B. Purwanto. 2004. Pengaruh Konstruk Relasional Pada Customer Refferals Dan Jumlah Jasa Yang Dibeli Dengan Umur Relasional Sebagai Variabel Pemoderasi (Studi Pada Bisnis Asuransi). Jurnal Ekonomi dan Bisnis (JEBI) UGM 19 (3).

Robbins, S. P., dan T. A. Judge. 2013. Organizational Behavior. NY: Prentice Hall

Tang, T. L.-P., dan A. H. S. Ibrahim. 1998. Antecedents of Organizational Citizenship Behavior Revisited: Public Personnel in the United States and in the Middle East Public Personnel Management 27 (4):529-550.

Trihardjanti,Ch. dan Irmawati,B. 2007. Analisis Perbedaan Organizational Citizenship Behavior Dosen Perguruan Tinggi Swasta Antara Pria dan Wanita di Kota Semarang.

World Insurance Outlook (2012)

Williams, L., \& Anderson, S. (1991). Job satisfaction and organizational commitment as predictors of Organizational citizenship and in-role behaviors. Journal of Management, 17, 601-617. 